\title{
Sensitivity of Sea Surface Temperature Simulation by an Ocean Model to the Resolution of the Meteorological Forcing
}

\author{
F. Chen, G. Shapiro, and R. Thain \\ School of Marine Science and Engineering, Plymouth University, Drake Circus, Plymouth PL4 8AA, UK \\ Correspondence should be addressed to G. Shapiro; gshapiro@plymouth.ac.uk
}

Received 31 October 2012; Accepted 3 February 2013

Academic Editors: C. Brunet, J. O. Herrle, G. L. Taghon, and M. Wang

Copyright (C) 2013 F. Chen et al. This is an open access article distributed under the Creative Commons Attribution License, which permits unrestricted use, distribution, and reproduction in any medium, provided the original work is properly cited.

\begin{abstract}
The effect on sea surface temperature (SST) predictions caused by varying atmospheric forcing within an ocean model is examined in the Celtic Sea, a typical shelf sea situated to the southwest of the British Isles. We use the 3D ocean circulation model POLCOMS, with $2 \mathrm{~km}$ resolution, 30 vertical layers, and two sets of meteorological forcing, at low $\left(1.6^{\circ}\right)$ and high $\left(0.11^{\circ}\right)$ horizontal resolutions. The model is validated against in situ and satellite observations. Comparisons made for the year 2008 show that increasing the resolution of the meteorological forcing does not necessarily lead to more accurate results in the modelled SST. The discrepancy between the low and high resolution cases was found to be the greatest in the summer, with the errors of the mean SST being $0.15^{\circ} \mathrm{C}$ and $1.15^{\circ} \mathrm{C}$, respectively. Overall, the most accurate reproduction of SST throughout the year is obtained using the low resolution atmospheric data. We show that this is due not to the resolution of the forcing per se, but to the differences between the meteorological models in mean values of parameters such as cloud cover, which in turn reduce the solar radiation flux reaching the sea surface in the oceanographic model.
\end{abstract}

\section{Introduction}

The quality of ocean simulations depends on a number of factors such as approximations in governing equations, errors introduced by the numerical scheme, uncertainties in input parameters, and atmospheric forcing. Relations between those uncertainties and the accuracy of a model's output have been a topic for a number of studies. Wright and Stocker [1] examined sensitivity of the meridional fluxes of heat and water as functions of model parameters as well as the significance of various model simplifications. They found that the results are relatively insensitive to the value of the horizontal diffusion coefficient provided it is of the order of $10^{3} \mathrm{~m}^{2} / \mathrm{s}$ or smaller. Incorporation of the realistic wind stress significantly improves the comparison with observational estimates. The effects of the vertical discretisation schemes on the accuracy density driven currents were studied by Ezer and Mellor [2], Legg et al. [3], and Shapiro et al. [4]. The effect of variation in initial and open boundary conditions on circulation in the North East Atlantic was studied by Wakelin et al. [5]. They found that on the continental shelf, the effect of using different ocean model initial and boundary conditions was small, whilst it was significant in the deeper oceanic regions. Berntsen et al. [6] studied the sensitivity of nonhydrostatic effects to the grid size and found that nonhydrostatic effects are small for the horizontal grid sizes larger than $50 \mathrm{~m} \mathrm{[6].}$

Probably the strongest effect on the quality of modelling of currents in a nontidal sea is the accurate representation of the meteorological parameters. For example, the basinwide circulation pattern and the temperature structure in the Black Sea produced by the same model are significantly dependent on the source of the meteorological input [7]. Atmospheric data of approximately the same resolution from two different sources, National Centers for Environmental Prediction (NCEP, USA) and Japanese 25 year Re-Analysis Project (JRA) sometimes provided very different circulation patterns and water column stratification.

Atmospheric forcing plays a significant role in controlling the dynamics of shelf seas, in the form of surface fluxes of heat, momentum, precipitation, and evaporation. Sensitivity studies are becoming increasingly important due to their particular role in improving accuracy of shelf sea models. Young and Holt [8] studied the sensitivity of salinity fields 


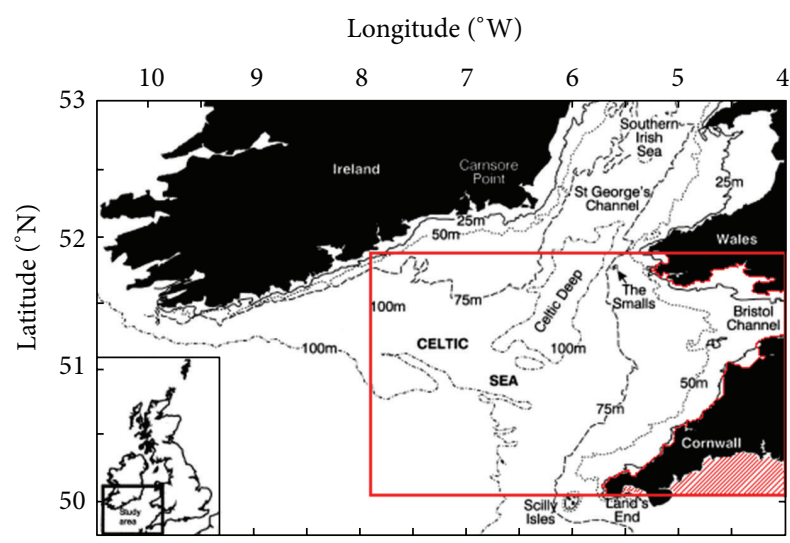

Figure 1: Bathymetric map of the Celtic Sea showing the study area (red rectangle).

produced by a 3D numerical model to boundary conditions and precipitation/evaporation in the Irish Sea. They concluded that investigating the sensitivity to the details of the meteorological forcing would be an obvious next step.

A recent sensitivity study by O'Neill et al. [9] examined the effect of varying ocean model resolution on the model skill in representing sea surface temperature and salinity in the Irish Sea. The authors showed that the NEMO model with $7 \mathrm{~km}$ resolution performed very similarly to the $1.8 \mathrm{~km}$ POLCOMS model when both used the same atmospheric forcing data set. The representation of the sea surface temperature was improved when meteorological forcing with higher spatial and temporal resolution was used. In particular, the use of higher resolution forcing was reduced the RMS error in sea surface temperature by $20-30 \%$.

In this paper we examine if the performance of an ocean model is improved when the data to force the model is taken from a higher resolution atmospheric model. Our study is conducted in the Celtic Sea, a typical European shelf sea situated to the southwest of the British Isles (Figure 1). The sea is encompassed by the coasts of southern Ireland, southwest Wales, Cornwall, and by the St George's Channel, the English Channel and the $200 \mathrm{~m}$ isobath of the continental shelf linking with the North Atlantic [10]. The Celtic Sea is a tidally dominated water basin, with the tidal stream amplitude varying from $0.25 \mathrm{~ms}^{-1}$ in the southwest to $2 \mathrm{~ms}^{-1}$ in the Bristol Channel $[11,12]$. It is also filled with mesoscale eddies which contribute to the formation of the residual (tidally averaged) circulation pattern [13]. The sea is strongly stratified with a sharp thermocline from April to November [14], which adds to the formation of density-driven currents. In the summer, the Celtic Sea features intense and persistent cyclonic baroclinic jet-like flow associated with the margins of a cold pool with saline bottom water [15].

We use two versions of a 3D ocean circulation model POLCOMS $[16,17]$ with $2 \mathrm{~km}$ resolution. The models are identical except for their meteorological forcing: the low resolution forcing was obtained from the National Centers for Environmental Prediction (NCEP-II, $1.6^{\circ}$ resolution), and the high resolution forcing obtained from the British
Atmospheric Data Centre (BADC, $0.11^{\circ}$ resolution). Both models are run for the year 2008, and comparisons are made with the sea surface temperature (SST) obtained from NASA POET (http://poet.jpl.nasa.gov/). Additionally the model with low resolution forcing was run from June to August 1998 for validation purposes, since this period coincides with a comprehensive survey carried out by Brown et al. [15] in the Celtic Sea. The high resolution meteo forcing for this period was not available.

\section{Methods and Data}

2.1. Ocean Model. The POLCOMS model is a three-dimensional primitive equation finite difference model that has been used successfully for modelling different regions of the world ocean, such as the European continental shelf [16-18], the Black Sea [19] the Rockall Bank [20], and the Celtic Sea [21]. POLCOMS has been used operationally by the UK Met Office for the European Shelf seas [22]. The model uses the Arakawa B grid in the horizontal [23], the terrain-following s-coordinate system of Song [24], and the Piecewise Parabolic Method advection scheme [25] which has low numerical diffusion. The $k-\varepsilon$ turbulent closure scheme is provided by embedded General Ocean Turbulence Model [26].

This model domain covers the Celtic Sea between $50.08^{\circ} \mathrm{N}$ to $51.83^{\circ} \mathrm{N}$ and $7.90^{\circ} \mathrm{W}$ to $4.00^{\circ} \mathrm{W}$, surrounded by the Cornish and Welsh coasts, and the extensive open boundary as shown by a red line in Figure 1. The model configuration is similar to that developed in [21]. The model uses an s-coordinate system with 30 vertical layers at horizontal resolution of $2 \mathrm{~km}$. The bathymetry was acquired from the ETOPO- 2 database with $1 / 30^{\circ}$ resolution [27] and smoothed by applying a $3 \times 3$ matrix filter. In order to exclude wetting and drying effects, numerical calculations were performed in the areas deeper than $5 \mathrm{~m}$. The temperature and salinity initial fields and boundary conditions were extracted from the World Ocean Database [28]. Simulations were initialised from the restart files produced by geostrophic runs, allowing the currents to spin up without losing initial temperature and salinity field as in [19]. The following minor amendments were introduced compared to the configuration used in [21]: (i) the model domain has been extended on the western side; (ii) the tidal forcing at the open boundaries now includes 11 constituents which are taken from the $1 / 30 \times 1 / 30^{\circ}$ TPXO 7.2 Regional Inverse Tide Model developed by the Oregon State University [29].

2.2. Atmospheric Forcing. POLCOMS uses the following 7 variables as the atmospheric forcing: $U$ and $V$ components of the wind at $10 \mathrm{~m}$ above sea surface, air temperature at $2 \mathrm{~m}$, atmospheric pressure, relative humidity, cloudiness, and precipitation rate. Downward solar radiation is calculated by the model from astronomical data and cloudiness. Two sets of atmospheric forcing are used for this study: (i) data from the British Atmospheric Data Centre (BADC, $0.11^{\circ}$ resolution) and (ii) data from the National Centers for Environmental Prediction (NCEP-II, approximately $1.6^{\circ}$ resolution), both of which have the same frequency of 6-hour interval.

Higher resolution BADC data produced by the Met Office North Atlantic European (NAE) unified model (UM) for 
TABLE 1: Summary of model simulations.

\begin{tabular}{|c|c|c|}
\hline $\begin{array}{l}\text { Simulations } \\
\text { ID }\end{array}$ & Atmospheric forcing & Period of simulation \\
\hline N98 & $\begin{array}{c}\text { NCEP }\left(1.6^{\circ} \text { resolution, } 6\right. \\
\text { hourly })\end{array}$ & 01 Jun 1998-15 Sep 1998 \\
\hline N08 & $\begin{array}{c}\text { NCEP }\left(1.6^{\circ} \text { resolution, } 6\right. \\
\text { hourly })\end{array}$ & 01 Jan 2008-31 Dec 2008 \\
\hline B08 & $\begin{array}{c}\text { BADC }\left(0.11^{\circ} \text { resolution, }\right. \\
6 \text { hourly })\end{array}$ & 01 Jan 2008-31 Dec 2008 \\
\hline
\end{tabular}

the operational weather prediction purpose was acquired from the British Atmospheric Data Centre (BADC) under the licensed agreement with the National Environmental Research Council (NERC) and the UK Meteorological Office (UKMO). NCEP Reanalysis-II data downloaded from NOAA PSD (NOAA/OAR/ESRL PSD, Boulder, Colorado, USA) is an improved version of the NCEP Reanalysis I model that fixed errors and updated parameterizations of physical processes. In order to carry out statistical comparison between two sets of data, both of them were interpolated onto the model grid as POLCOMS does internally.

2.3. Model Simulations. In total, three sets of simulations have been carried out, see Table 1: two with NCEP low resolution forcing, and one with BADC high resolution forcing. For the purpose of model validation throughout the water column, the period for the simulation N98 has been chosen so that it overlaps with extended in situ measurements by Brown et al. [15] who used an undulating CTD probe. The period for simulations N08 and B08 was chosen based on the availability of high resolution BADC data. The outputs of model simulations were stored with hourly intervals for the whole period and contain 3D data on $U$ and $V$ currents, temperature, and salinity. The model outputs for the year 1998 are synchronised in time and space with observations by Brown et al. [15] as detailed in the following section. The model skill is assessed by calculating statistical parameters (the bias of the mean, root mean square of the demeaned fields, and the correlation parameter), and calculating the Willmott skill parameter [30]. Model outputs are also validated against the observed SST, obtained from NASA (http://poet.jpl.nasa.gov/). Simulations N08 and B08 are used to assess sensitivity of various model outputs to the resolution of the atmospheric forcing.

2.4. Observational Data. The temperature and salinity structures of the Celtic Sea were examined by Brown et al. [15] using a towed undulating CTD (Scanfish) on 19 transects in the Celtic Sea between 26 August and 5 September 1998 (hereafter referred to as Cor98). We use 4 of these transects (numbered 182, 202, 189, and 187) which are located within the model domain and are shown in Figure 2. The data cover the depth range between $4 \mathrm{~m}$ below sea surface and $5 \mathrm{~m}$ above seabed and have a $1 \mathrm{~m}$ vertical resolution and a horizontal separation of approximately $150-500 \mathrm{~m}$.

Due to the difference in resolution between the Cor98 data $(1 \mathrm{~m}$ in the vertical by $150-500 \mathrm{~m}$ in the horizontal) and the POLCOMS model ( $1-4 \mathrm{~m}$ in the vertical by $2 \mathrm{~km})$,

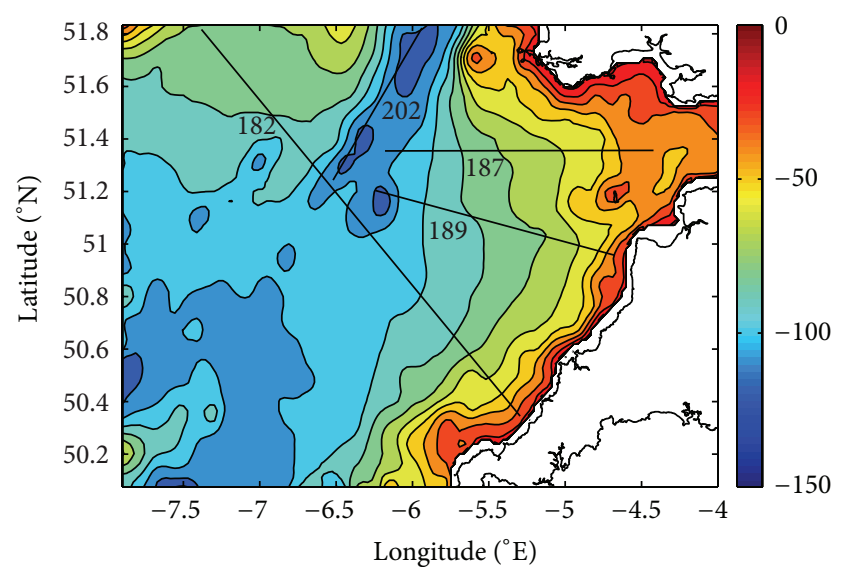

FIGURE 2: Locations of four Scanfish sections selected to validate the model, indicated as the black solid lines and numbered as 182, 202, 189 , and 187, respectively. The colour scale shows bathymetry.

a common grid with an intermediate resolution $(2 \mathrm{~m}$ in the vertical by $1 \mathrm{~km}$ in the horizontal) is used to carry out comparisons. First the original Cor98 data are interpolated into the common grid along each transect. Interpolation has been done using the Kriging method with a search radius of $1.5 \mathrm{~km}$ in the horizontal and $5 \mathrm{~m}$ in the vertical and then interpolating the $3 \mathrm{D}$ hourly POLCOMS outputs onto the same grid. As the Scanfish transects took several hours to complete, they have been split into 1-hour segments to match the model output for the same hour. Finally, a synthetic model output from individual 1-hour blocks was generated to cover the whole period of the transect and compare the model output and the observations.

The sea surface temperature (SST) for model validation was obtained from high quality MODIS (Moderate Resolution Imaging Spectroradiometer) Aqua satellite data (http://poet.jpl.nasa.gov/) at $4 \mathrm{~km}$ resolution. These data are used for validation of N08 and B08 observations. MODIS Aqua data is not available for the year of 1998.

2.5. Methods of Analysis. Here we apply statistical methods to make the following comparisons between $2 \mathrm{D}$ atmospheric and oceanographic data fields:

(i) NCEP against BADC meteo data;

(ii) POLCOMS model against undulating CTD observations;

(iii) POLCOMS with NCEP forcing against MODIS Aqua SST;

(iv) POLCOMS with BADC forcing against MODIS Aqua SST;

(v) POLCOMS with NCEP forcing against POLCOMS with BADC forcing.

Consider two variables $M_{n}$ and $O_{n}$, (e.g., obtained from a model and observations) which are defined at the same $N$ discrete points either in space or time. The bias 
TABLE 2: Statistical summary for temperature in each layer of Section 182.

\begin{tabular}{lcccccc}
\hline Layers & Depth $(\mathrm{m})$ & $\mathrm{BoM}\left({ }^{\circ} \mathrm{C}\right)$ & RMSe $\left({ }^{\circ} \mathrm{C}\right)$ & $R(0-1)$ & $S(0-1)$ & Data points sampled \\
\hline A: surface mixed layer & $0-17$ & -0.016 & 0.39 & 0.79 & 0.89 & 2040 \\
B: stratified layer & $17-40$ & -0.34 & 1.26 & 0.76 & 0.82 & 2244 \\
C: intermediate layer & $40-70$ & -1.4 & 0.92 & 0.77 & 0.71 & 2610 \\
D: bottom layer & $70-110$ & -0.79 & 0.54 & 0.86 & 0.70 & 1133 \\
Whole section & $0-110$ & -0.72 & 0.99 & 0.92 & 0.93 & 8024 \\
\hline
\end{tabular}

Abbreviations: BoM is the bias of mean; RMSe is the root mean square error; $R$ is the correlation coefficient; $S$ is the Willmott skill parameter.

TABLE 3: Statistical summary of temperature of sections 202, 187, and 189.

\begin{tabular}{lccccc}
\hline Sections & RMSe $\left({ }^{\circ} \mathrm{C}\right)$ & $\mathrm{BoM}\left({ }^{\circ} \mathrm{C}\right)$ & $R(0-1)$ & $S(0-1)$ & Data points sampled \\
\hline 202 & 0.53 & -0.35 & 0.98 & 0.98 & 2795 \\
187 & 0.81 & -0.077 & 0.81 & 0.87 & 2886 \\
189 & 0.83 & -0.17 & 0.95 & 0.97 & 4335 \\
\hline
\end{tabular}

Abbreviations: BoM is the bias of mean; RMSe is the root mean square error; $R$ is the correlation coefficient; $S$ is the Willmott skill parameter.

of the mean (BoM) measures the average magnitude of differences between the two variables and is given by

$$
\mathrm{BoM}=\frac{\sum_{n=1}^{N}\left(M_{n}-O_{n}\right)}{N}
$$

The Root Mean Square error (RMSe) gives an estimate of random differences between two fields. In order to isolate the effect of BoM from RMSe, it is applied to the deviations from the mean rather than to the original values. The RMSe is defined by the equation

$$
\text { RMSe }=\left\{\frac{1}{N} \sum_{n=1}^{N}\left[\left(M_{n}-\bar{M}\right)-\left(O_{n}-\bar{O}\right)\right]^{2}\right\},
$$

where $\bar{M}$ and $\bar{O}$ are the means of two patterns over the discrete points.

The correlation coefficient quantifies the strength and direction of the linear relationship between two variables and is defined as

$$
R=\left\{\frac{(1 / N) \sum_{n=1}^{N}\left(M_{n}-\bar{M}\right)\left(O_{n}-\bar{O}\right)}{\sigma_{m} \sigma_{o}}\right\},
$$

where $\sigma_{m}$ and $\sigma_{o}$ are the standard deviations of the two variables.

The Willmott skill parameter [30] is another measure which is used to assess how close two sets of data are. It is defined as

$$
S=1-\frac{\sum\left|M_{n}-O_{n}\right|^{2}}{\sum\left(\left|M_{n}-\bar{M}\right|+\left|O_{n}-\bar{O}\right|\right)^{2}} .
$$

The value of Skill $=1$ represents perfect match while Skill $=0$ means no match.

\section{Results and Discussion}

3.1. Assessment of Model Performance. The performance of the model is evaluated by comparisons of model results
(Simulation N98) with observed Scanfish data collected using towed undulating CTD on four sections in AugustSeptember 1998. Main features of the transects and their comparison with model outputs are discussed below.

3.1.1. Section 182. Section 182 (Figure 2) crosses the model domain from the model western boundary to the Cornish coast over the Celtic deep, capturing main thermal features of the Celtic Sea. The comparison of temperature structure between Cor98 Scanfish data and POLCOMS is shown in Figure 3. The left panel shows the temperature structure observed on 27 August in 1998 while the right one describes the model results. The model reproduces the complex thermal features observed, predicting the intense thermocline through the centre to the south. Furthermore, small variations along the thermocline due to the interaction between wind induced mixing and bottom tidal mixing are modelled accurately, giving a surprising agreement here.

The cold bottom dome $\left(<11^{\circ} \mathrm{C}\right)$ over the Celtic deep (distance $95-160 \mathrm{~km}$ from the starting point of the transect) is resolved clearly, although with slightly colder water than observed. A secondary dome expanding from $160 \mathrm{~km}$ to $200 \mathrm{~km}$ associated with the bottom front is also reproduced successfully by this model, but with less horizontal diffusion in the modelled results. The modelled surface temperature shows a peak of $\sim 17^{\circ} \mathrm{C}$ ranging from $100 \mathrm{~km}$ to $220 \mathrm{~km}$ is similar to observations, although it is approximately $0.5^{\circ} \mathrm{C}$ colder near the Cornish coast $(230-250 \mathrm{~km})$, most likely resulting from the insufficient surface heat flux. However, the north-western margin of the cold bottom dome (close to the open boundary, left of $100 \mathrm{~km}$ mark in Figure 3) is predicted without showing the front below $50 \mathrm{~m}$ which is evident in observations. As the tides within this model were carefully validated, it is unlikely that this discrepancy is due to insufficient magnitude of tidal currents. A potential reason for reduced accuracy near the open boundary of the domain is the poor resolution of boundary temperature and salinity data extracted from $0.25^{\circ}$ monthly climatology of World Ocean Atlas [28]. Figure 3 shows, as well as other model 


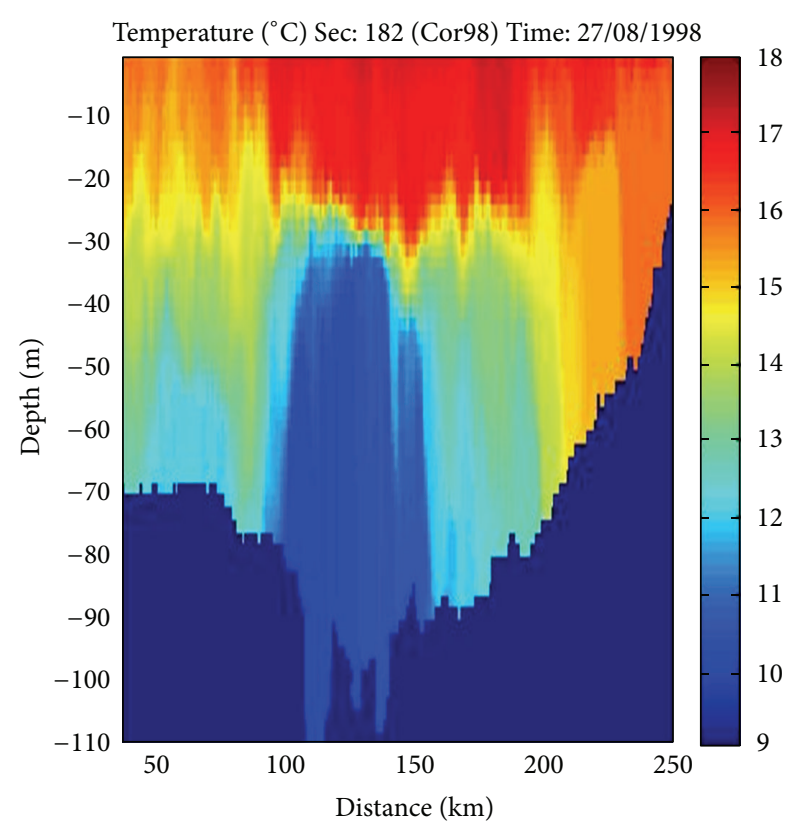

(a)

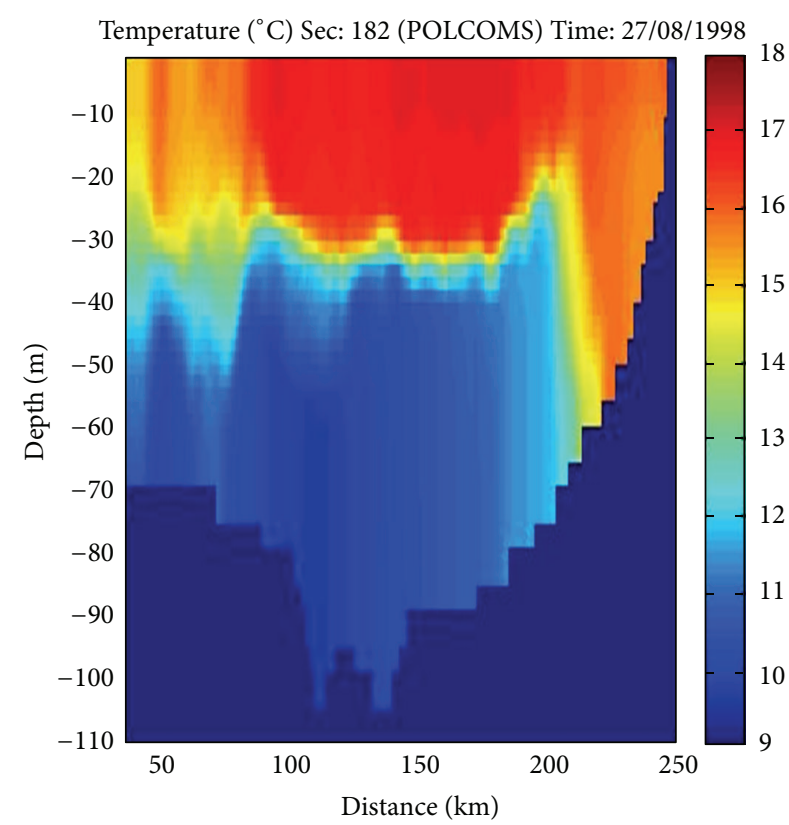

(b)

FIGURE 3: Comparison of temperature structure along Section 182 between Cor98 Scanfish data (a) and model outputs (b).

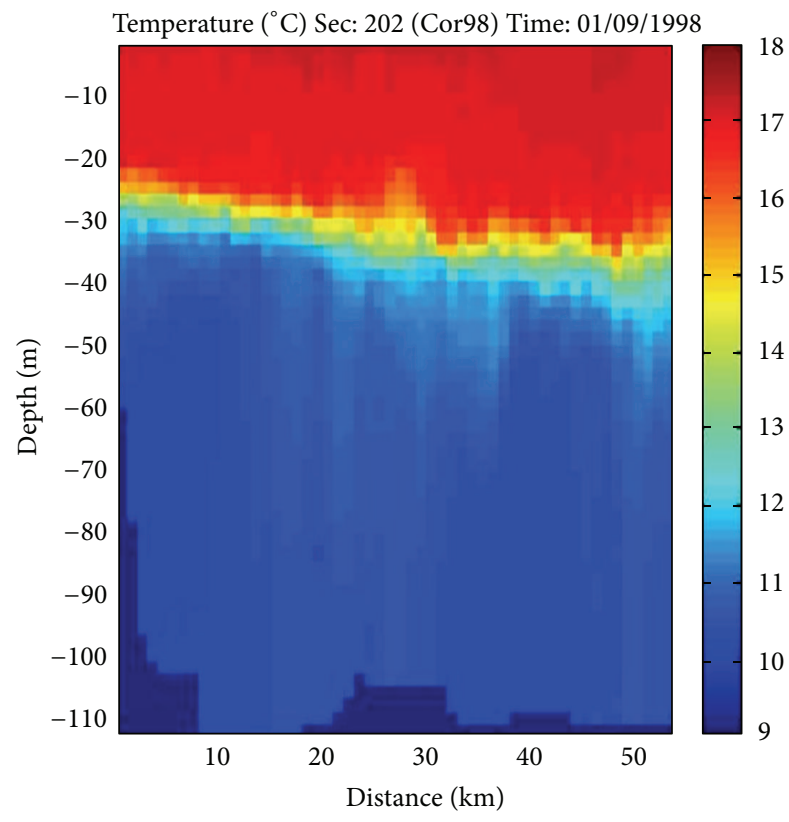

(a)

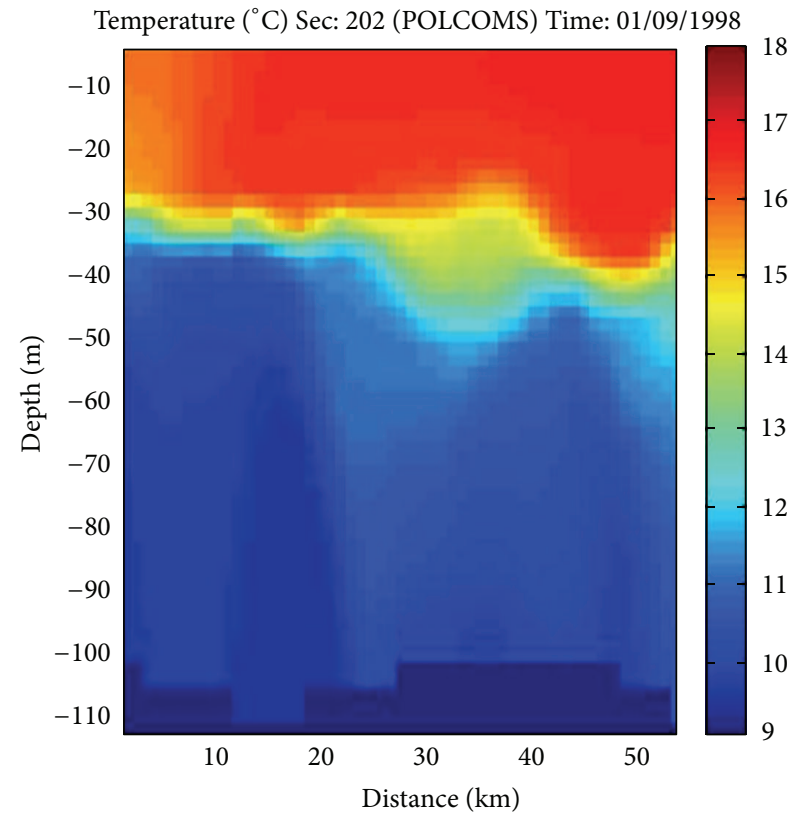

(b)

FIgURE 4: Comparison of temperature structure along Section 202 between Cor98 Scanfish data (a) and model outputs (b).

outputs not shown here, that at the western boundary water column is much colder in August than observed, particularly below a depth of $30 \mathrm{~m}$. This cold water is advected horizontally from the open boundary thus hindering formation of the front by tidal mixing near the $80 \mathrm{~km}$ mark in Figure 3.

In order to assess quantitatively the model skill, Section 182 is divided into four layers in the vertical direction, labelled as A (surface mixed layer), B (stratified layer), C (intermediate layer), and D (bottom layer), respectively. The statistical analysis is summarised in Table 2, which also shows the depth for each layer and the number of points sampled for statistical calculation.

Table 2 shows a very good model skill in the surface mixed layer $\mathrm{A}$, with $\mathrm{BoM}=-0.02^{\circ} \mathrm{C}$ (model is slightly colder) and RMSe less than $0.4^{\circ} \mathrm{C}$. Despite missing one of the temperature fronts in the bottom layer, the model still performs reasonably 
TABLE 4: Summary of differences between BADC and NCEP meteorological data.

\begin{tabular}{cccccccccccccc}
\hline & & \multicolumn{3}{c}{ Winter } & \multicolumn{3}{c}{ Spring } & \multicolumn{3}{c}{ Summer } & \multicolumn{3}{c}{ Autumn } \\
& & ME & RMSe & $R$ & ME & RMSe & $R$ & ME & RMSe & $R$ & ME & RMSe & $R$ \\
\hline \multirow{4}{*}{ Meteo forcing } & Air temperature $\left({ }^{\circ} \mathrm{C}\right)$ & 0.51 & 0.44 & 0.7 & -0.81 & 0.34 & 0.57 & 0.01 & 0.30 & 0.38 & 0.35 & 0.37 & 0.51 \\
& Total cloud cover $(\%)$ & 16.77 & 9.9 & 0.2 & 19.63 & 10.6 & 0.2 & 23.3 & 8.96 & 0.13 & 22.5 & 8.46 & 0.2 \\
& Pressure $(\mathrm{Pa})$ & 54.6 & 53.1 & 0.82 & 2.3 & 63.0 & 0.73 & 11.6 & 49.3 & 0.79 & 12.1 & 43.5 & 0.83 \\
& Relative humidity (\%) & -4.8 & 2.3 & 0.33 & 1.91 & 2.2 & 0.38 & -1.2 & 2.2 & 0.2 & -4.4 & 2.1 & 0.33 \\
& Precipitation $\left(\mathrm{kg}^{\prime} \mathrm{m}^{2} /\right.$ day) & 0.02 & 1.98 & 0.31 & 0.9 & 2.46 & 0.28 & 0.43 & 2.87 & 0.30 & 0.2 & 2.4 & 0.31 \\
& $U$-wind $\left(\mathrm{ms}^{-1}\right)$ & -0.26 & 0.85 & 0.48 & -0.19 & 0.82 & 0.46 & -0.25 & 0.82 & 0.32 & -0.4 & 0.75 & 0.5 \\
& $V$-wind $\left(\mathrm{ms}^{-1}\right)$ & -1.14 & 0.78 & 0.56 & -0.48 & 0.83 & 0.47 & -1.19 & 0.77 & 0.55 & -0.6 & 0.86 & 0.54 \\
\hline
\end{tabular}

Abbreviations: BoM is the bias of mean; RMSe is the root mean square error; $R$ is the correlation coefficient.

TABLE 5: Summary of model sensitivities to meteorological forcing.

\begin{tabular}{llccccccccccccc}
\hline & & \multicolumn{3}{c}{ Winter } & \multicolumn{3}{c}{ Spring } & \multicolumn{3}{c}{ Summer } & \multicolumn{3}{c}{ Autumn } \\
& & ME & RMSe & $S$ & ME & RMSe & $S$ & ME & RMSe & $S$ & ME & RMSe & $S$ \\
\hline \multirow{2}{*}{ SST $\left({ }^{\circ} \mathrm{C}\right)$} & NCEP versus POET & -0.13 & 0.38 & 0.73 & 0.15 & 0.47 & 0.63 & 0.15 & 0.58 & 0.62 & 0.02 & 0.58 & 0.62 \\
& BADC versus POET & -0.19 & 0.38 & 0.71 & -0.18 & 0.56 & 0.62 & -0.61 & 0.73 & 0.42 & -0.25 & 0.49 & 0.42 \\
\hline
\end{tabular}

Abbreviations: BoM is the bias of mean; RMSe is the root mean square error; $S$ is the Willmott skill parameter.

well there with slightly higher RMSe of $0.92^{\circ} \mathrm{C}$. Although the thermocline location and variations are well reproduced, given the complexity of the temperature pattern in the stratified layer, the temperature difference in layer B is higher $\left(\mathrm{RMSe}=1.26^{\circ} \mathrm{C}\right)$ than in other layers. In terms of model performance, the model demonstrates good accuracy in modelling thermal structures of the Celtic sea, giving high values for both correlation coefficient $(R=0.77-0.92)$ and the Willmott skill parameter $(S=0.70-0.93)$. The values of BoM, RMSe, correlation coefficient, and model skill for the transect as whole are $\mathrm{BoM}=-0.72^{\circ} \mathrm{C}$, RMSe $=0.99^{\circ} \mathrm{C}$, and $S=0.93$, which is similar to the performance of the best operational models.

3.1.2. Section 202. Section 202 (Figure 2) is located to the northwest of the model domain, along the axis of the Celtic deep. The comparison of thermal structure between the model and observations is shown in Figure 4. According to both the model and observations, the Celtic deep is strongly stratified with an intense thermocline at a depth of approximately $30 \mathrm{~m}$. The temperature structure along this section is well resolved by the model, predicting the precise location of the thermocline. In the surface mixed layer, the model underestimates temperature by $\sim 0.5^{\circ} \mathrm{C}$, presumably due to insufficient surface heat flux. Two bottom cold pools (at $0-25 \mathrm{~km}$ and $30-54 \mathrm{~km}$ marks) are also reproduced, although the modelled water is slightly colder than observed. Such discrepancy is probably resulted from the errors in the initial and boundary conditions which were taken from relatively coarse climate data. As examined by Wakelin et al. [5], the effect of initial temperature and salinity conditions on the model outputs can be neglected after 15 months of model time, and then the meteorological forcing becomes dominant. For this study the model outputs are taken from the 3rd month of the model time, so that the effect of initial field is reduced but cannot be ignored completely; however, the effect of boundary conditions is felt at the edges of model domain independently of the length of simulation. At the north-eastern end of this transect, the thermocline jumps suddenly from depth $\sim 33 \mathrm{~m}$ to $\sim 28 \mathrm{~m}$, which is not consistent with the observations. This is likely to be the effect of errors in the open boundary condition. A statistical summary for this transect is given in Table 3.

3.1.3. Section 189. Section 189 (Figure 2) reveals a strong thermocline at a depth $\sim 30 \mathrm{~m}$, associated with a series of bottom fronts as shown in Figure 5. The intense stratification predicted is similar to the observations. At a distance of $0-$ $20 \mathrm{~km}$ the bottom cold water is reproduced accurately by the model, as well as the associated bottom fronts. They are, however, more diffuse in comparison with the observations. The location of the coastal front at $100 \mathrm{~km}$ is also modelled well, although it is slightly displaced and diffused compared to the observations. A possible reason for this is the excessive tidal mixing at $100-200 \mathrm{~km}$, resulting from the inaccurate representation of bathymetry by ETOPO2 data used in the model.

3.1.4. Section 187. Section 187 (Figure 2) is positioned to the north of Section 189, crossing the margin of the Celtic deep eastwards to the Bristol Channel. As shown in Figure 6, the model provides a temperature distribution close to that observed, with a strong stratification at a depth of $\sim 35 \mathrm{~m}$ and a well-mixed water column near the Bristol Channel. However, the bottom front in the model is not far enough eastwards. As we do not take into account the river input near the Bristol Channel, the resulting lack of freshwater input in this region leads to insufficient buoyancy inputs, thus contributing to a less accurate location of the bottom front compared to other transects.

The statistical properties of Sections 202, 187, and 189 are summarised in Table 3 . The data points for statistical calculations are sampled from the entire section. The thermal 


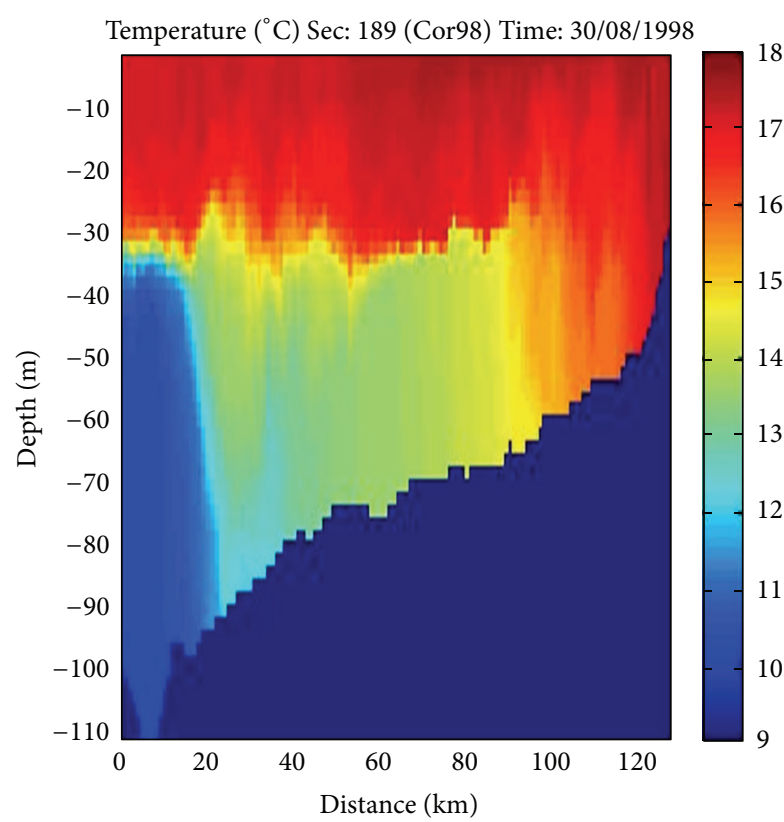

(a)

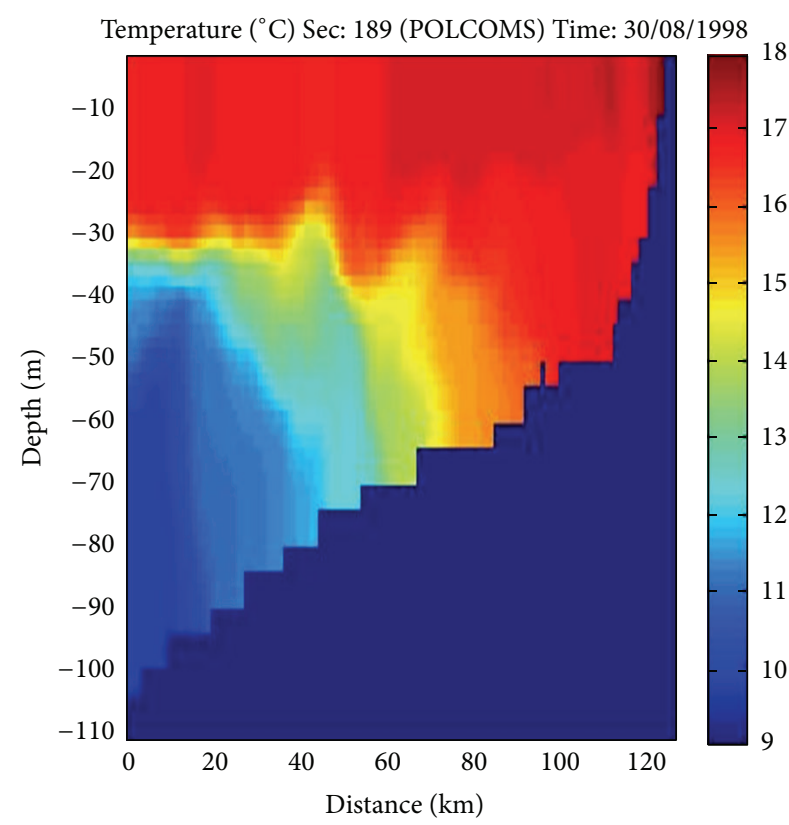

(b)

FIGURE 5: Comparison of temperature structure along Section 189 between Cor98 Scanfish data (a) and model outputs (b).

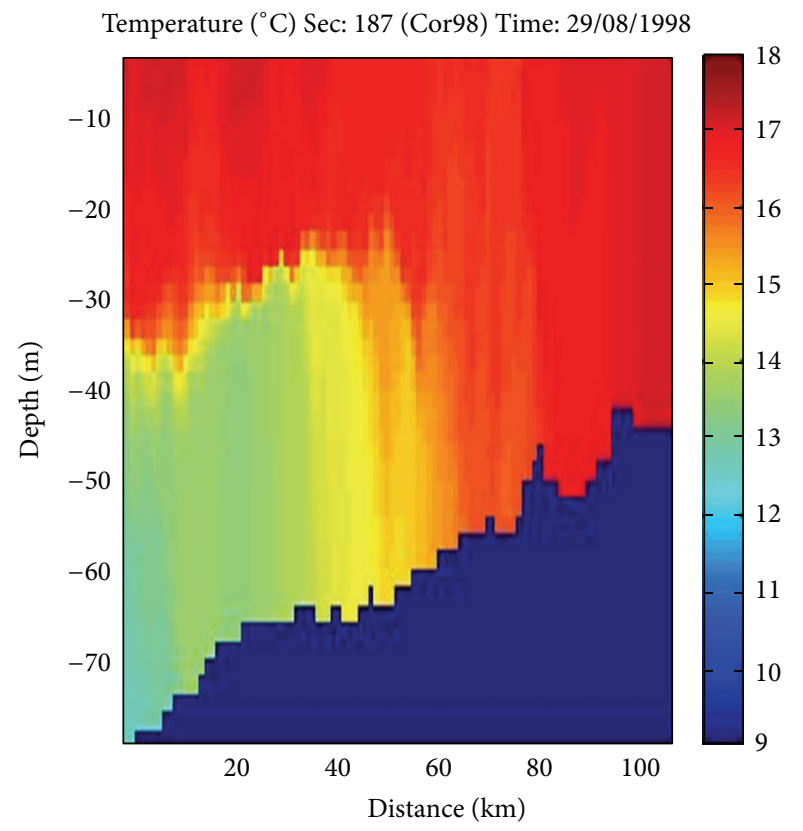

(a)

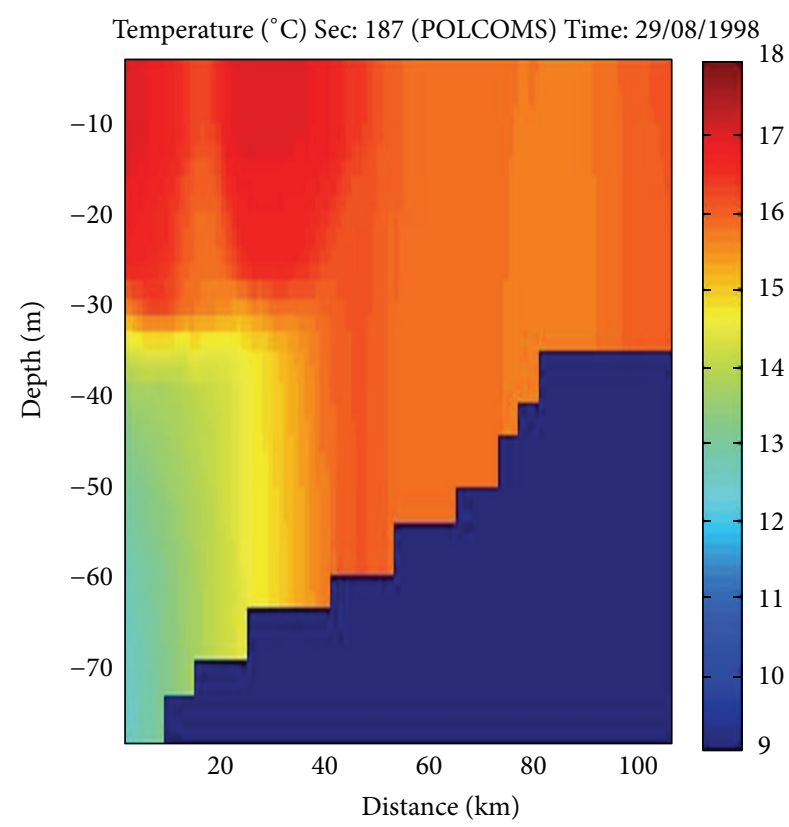

(b)

Figure 6: Comparison of temperature structure along Section 187 between Cor98 Scanfish data (a) and model outputs (b).

structures of the transect are well resolved with high correlation coefficients and low errors (biases) in the mean values. The values of the demeaned RMSe between the model and observation on all three sections are slightly higher but still not exceeding $1^{\circ} \mathrm{C}$. The model skill is as high as $S=0.87-0.98$, and the errors at the end of the transects are caused mainly by uncertainties in the boundary temperature conditions. Overall, the data shown in Table 3 confirm the high skill of the model in representing the temperature structure in the Celtic Sea, both at the surface and within the water column.

\subsection{Sensitivity Analysis}

3.2.1. Variations in Meteorological Forcing. A statistical intercomparison has been carried out to identify differences between BADC and NCEP meteorological forcing. In all 


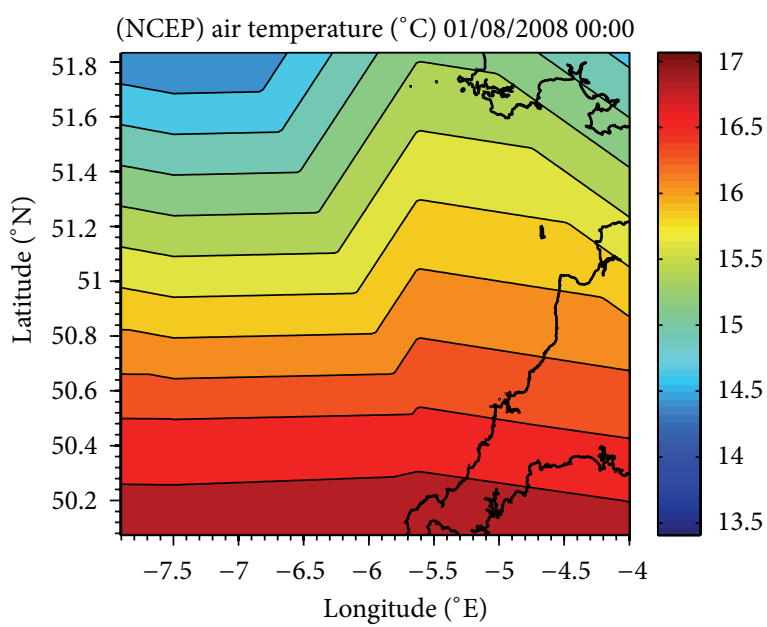

(a)

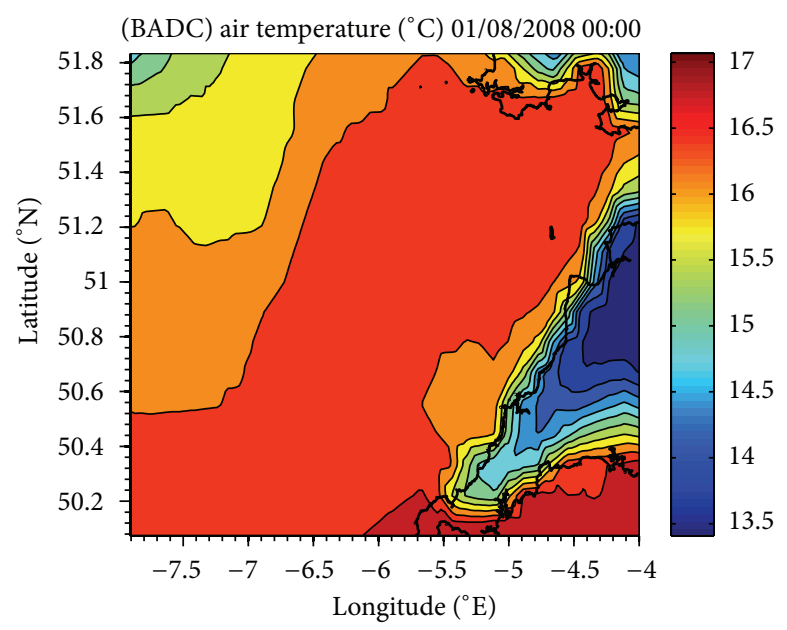

(b)

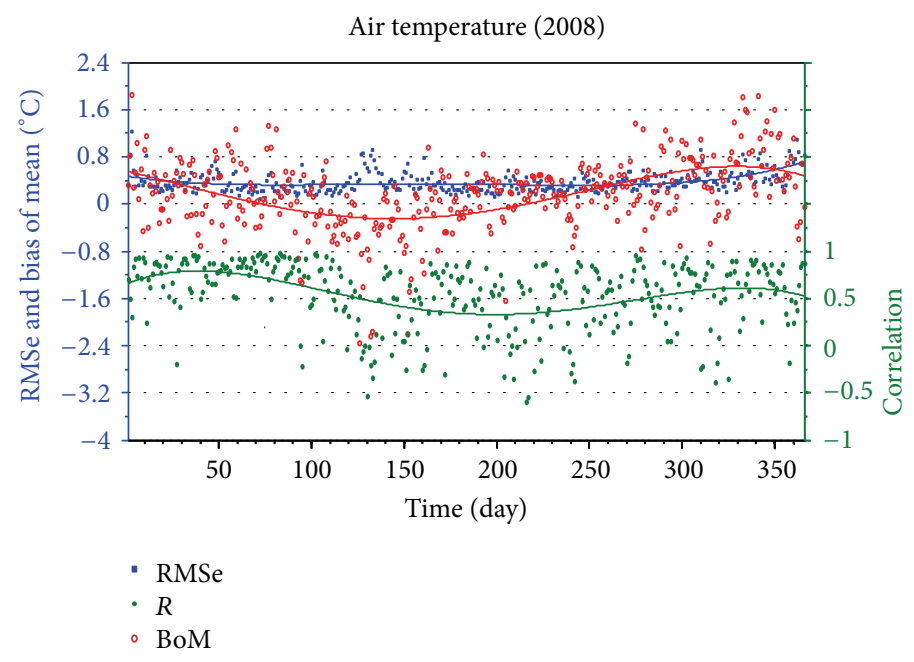

(c)

FIGURE 7: Sample air temperatures at $2 \mathrm{~m}$ from NCEP (a) and BADC (b) and the statistical differences for the year 2008 (c).

statistical comparisons, the data from NCEP has been considered as the reference field, that is, the O-variable in (1)(4). The upper panel in Figure 7 shows air temperature at $2 \mathrm{~m}$ above sea level on August 1, 2008 from NCEP and BADC. The lower panel in the same figure shows a time series of statistical measures of the difference between the two fields. The data for calculation of the statistics are taken over the whole model domain (i.e., excluding land points) for each 6-hour time point. The spatial patterns on the upper panel are very different, and the high resolution BADC data captures clearly the differences between land and sea areas. The BADC data are warmer in winter, giving a time averaged $\mathrm{BoM}=0.51^{\circ} \mathrm{C}$, and significantly cooler in spring with an average $\mathrm{BoM}=-0.81^{\circ} \mathrm{C}$; they are slightly cooler in the summer (negative BoM) giving a typical difference of $\left(-0.3^{\circ} \mathrm{C}\right)$ to $\left(-0.4^{\circ} \mathrm{C}\right)$. The discrepancies measured by demeaned RMSe over the whole year are small with a typical value of $0.25-0.4^{\circ} \mathrm{C}$. However the correlation coefficient is quite low $R=0.4-0.5$ indicating dissimilarity in the spatial pattern of air temperature.
The difference in the cloud cover between NCEP and BADC, as shown on the upper panel in Figure 8, is particularly strong. The high resolution BADC data capture smallscale variations, both over the sea and land. The cloudiness from BADC data is consistently about $20 \%$ higher than from NCEP. The demeaned RMSe is relatively small at about $10 \%$ but a very low correlation coefficient $(R=0.2-0.3)$ indicates a poor match between the spatial patterns of clouds provided by NCEP and BADC.

The statistics covering all four seasons of the year (winter: December, January, and February; spring: March, April, and May; summer: June, July, and August; and autumn: September, October, and November) and all 7 atmospheric variables used by the ocean model are summarized in Table 4 . The bias of the mean (BoM), demeaned root-mean-squared errors (RMSe) and correlation coefficient $(R)$ are calculated using daily NCEP and BADC data. The mean sea level pressures from both data sets are very similar with extremely low bias $(0.12-0.55 \mathrm{hPa})$ and RMSe $(0.44-0.63 \mathrm{hPa})$, and a high 
(NCEP) total cloud cover (\%) 04/08/2008 00:00

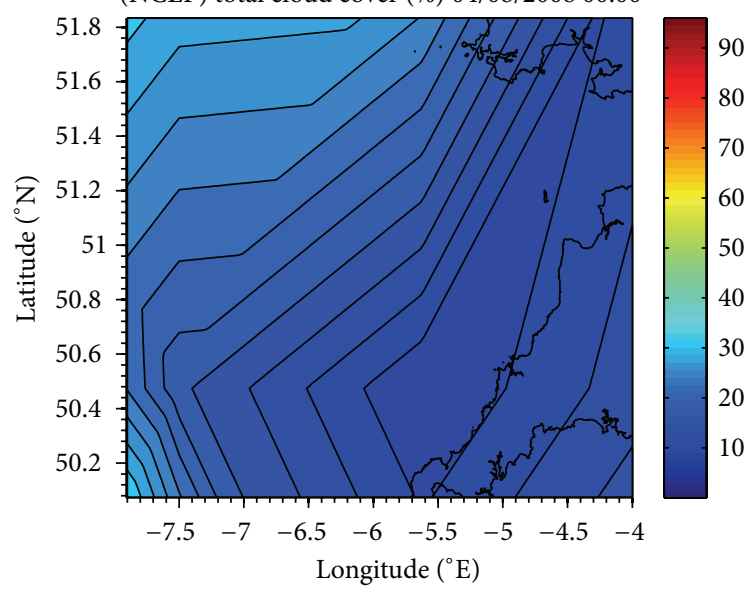

(a)

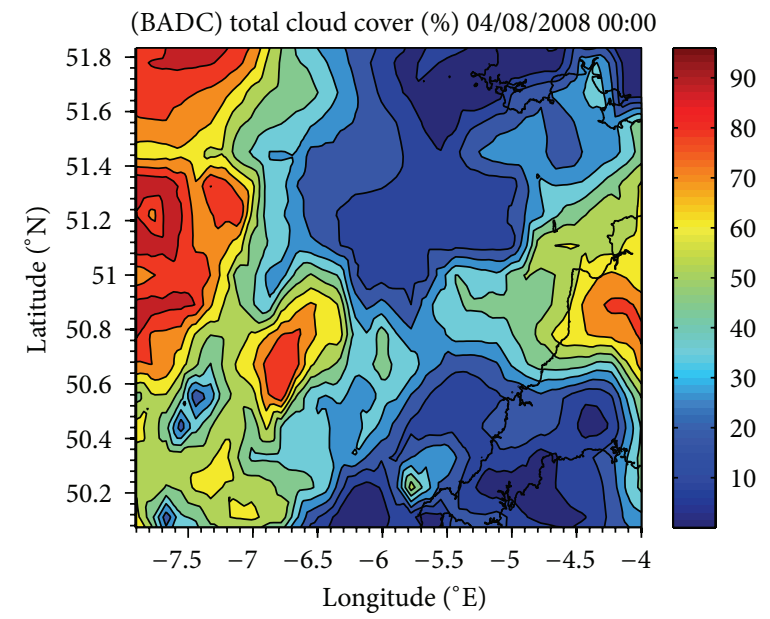

(b)

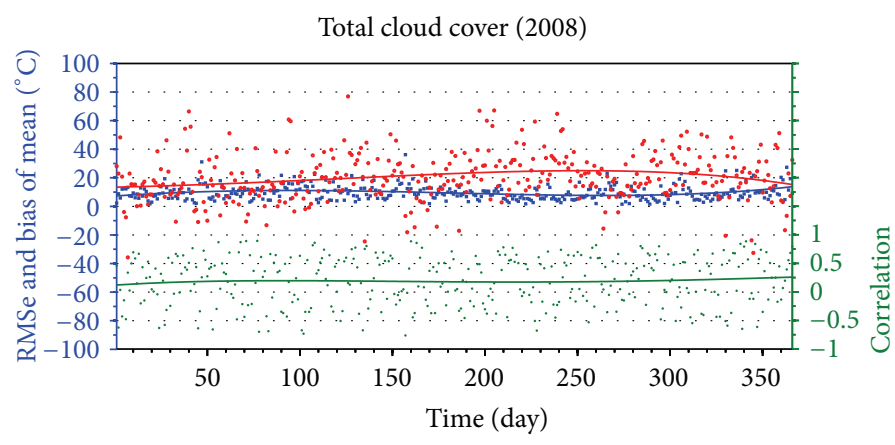

- RMSe

- $R$

- BoM

(c)

FIGURE 8: Sample total cloud cover (\%) from NCEP (a), BADC (b) and the statistical differences for the year 2008 (c).

correlation coefficient $(R=0.73-0.83)$. Although the relative humidity and precipitation have low biases and RMSe, the spatial patterns are quite dissimilar with low correlation coefficients. The wind speed of BADC is consistently lower than that of NCEP, and spatial patterns are different.

3.2.2. Variations in the Modelled Sea Surface Temperature. The 8-day averaged SST charts simulated by the two versions of POLCOMS model forced by BADC and NCEP data for the year 2008 have been compared with the remote sensed data obtained from NASA POET (http://poet.jpl.nasa.gov/). Compared to the daily SST data, the 8-day satellite data have a better spatial coverage due to cloud filtering. The simulated and observed 8-day averaged SST are presented in Figure 9(a), whilst the corresponding statistical comparisons are illustrated in Figure 9(b) (NCEP minus POET) and Figure 9(c) (BADC minus POET). The time averaged values for four seasons of 2008 are summarized in Table 5.

The difference between SST produced with BODC forcing and POET data increases consistently from late spring, reaching the peak point at the end of August, whereas the SST from the model forced by NCEP data gives a much better match with observations. The main reason for the difference between simulated SST obtained with BADC and NCEP data is that these data sets have significantly different values for the cloud cover, and hence downward solar radiation. In the summer, the SST from simulation forced by NCEP is overestimated by only $0.15^{\circ} \mathrm{C}$ while the model using BADC predicts much colder SST $\left(-0.61^{\circ} \mathrm{C}\right)$. The discrepancy reaches the value of $\mathrm{BoM}$ as high as $\left(-1.15^{\circ} \mathrm{C}\right)$ in late August.

The length scales of most energetic dynamic features in the atmosphere are defined by the Rossby radius of deformation, which is about $1000 \mathrm{~km}$ (the typical size of a cyclone). However submesoscale atmospheric patterns, such as patchiness in the cloud cover, could result in smaller scale variations of both the wind and solar radiation, hence creating a direct link between these smaller atmospheric features and the ocean mesoscale variability, which has a natural length scale of $10-20 \mathrm{~km}$ in a shelf sea.

Our analysis indicates that in the Celtic sea, the SST produced by the same model is extremely sensitive to variations in meteorological forcing during the summer. The results support the conclusion by O'Neill et al. [9] who claimed that the resolution of surface forcing has significant impact on the seasonal cycle of sea surface and bottom temperatures. However, our results show that the main reason 


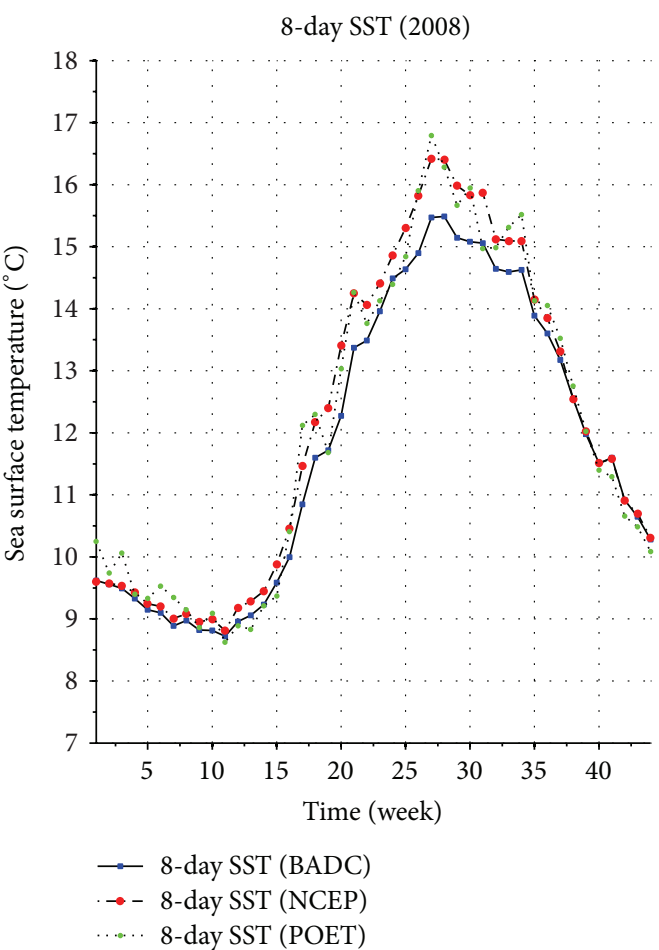

(a)

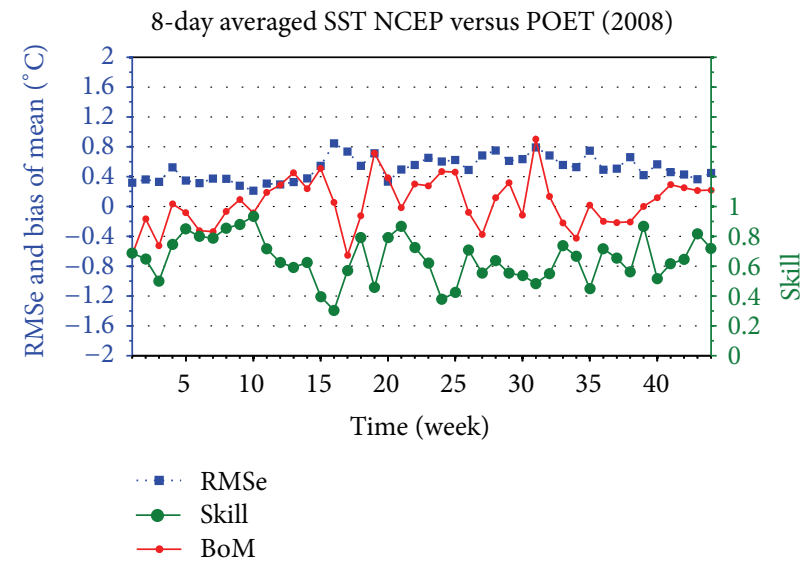

(b)

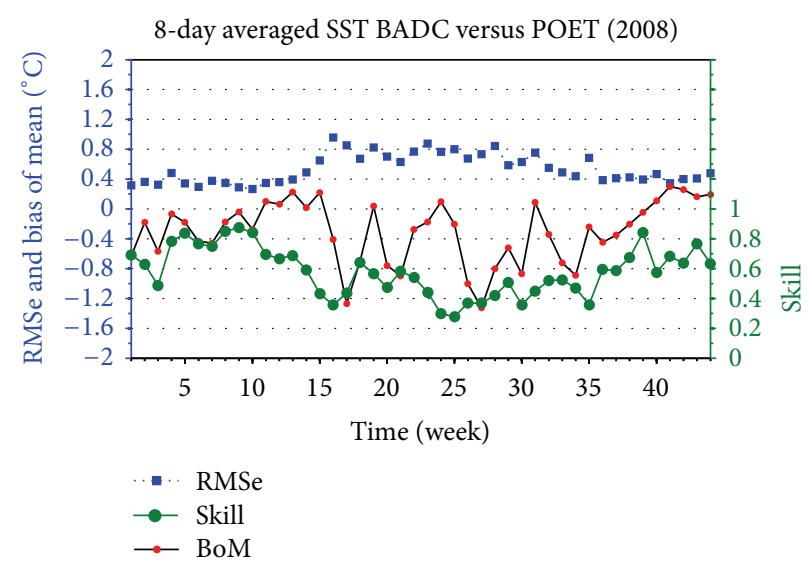

(c)

FIGURE 9: (a) The time line of 8-day averaged sea surface temperature from models driven by BADC and NCEP forcing and remotely sensed data from NASA POET. (b) Statistical differences between SST simulated with NCEP forcing and satellite data as a function of time. (c) Statistical differences between SST simulated with BADC forcing and satellite data as a function of time.

behind the differences is not the resolution of the forcing as such, but a significant difference in the mean values of cloudiness, wind speed, and air temperature. These factors control the majority of sea-air heat exchange and hence the sea surface temperature. The total cloud cover in BADC data is consistently much higher than that of NCEP, so that the resulting solar short wave radiation is lower, which in turn leads to inadequate surface heat flux being transferred to the ocean. This effect is partly compensated by lower winds represented in BADC, which reduces evaporation and hence the loss of latent heat from the sea. Lower air temperatures in the spring and the beginning of summer in the BADC data also contribute to lower SST produced by the model. In contrast to the situation in the Irish Sea reported by O'Neill et al. [9], higher resolution meteo data over the Celtic Sea do not necessarily result in better representation of the SST by the ocean model. To the contrary, it is the low resolution NCEP data which resulted in better simulation of the SST, particularly in the summer months.

\section{Conclusions}

The ability of the optimally configured POLCOMS model to resolve vertical thermal structures in the Celtic Sea is assessed 
by comparisons of model simulations with an extensive set of observational data (4 Scanfish sections selected for this study) collected in the Celtic Sea in 1998. The analysis reveals a good model skill, with the mean deviations of modelled and observed temperatures of $-0.72^{\circ} \mathrm{C},-0.35^{\circ} \mathrm{C}$, $-0.08^{\circ} \mathrm{C}$, and $-0.17^{\circ} \mathrm{C}$ for the transects $182,202,189$, and 187 , respectively. The Willmott model skill parameter on the same transects is as high as $0.93,0.98,0.87$, and 0.97 , respectively. The intercomparison between high resolution BADC meteo forcing data and coarser resolution NCEP data demonstrates strong dissimilarities, which result in differences in the SST produced by the ocean model driven by those data. Our results indicate that simulated SST is less sensitive to the differences between high resolution BADC and low resolution NCEP data during the winter and spring despite significant differences in the meteo data.

During the summer and autumn, however, the modelled SST hindcasts fit the observations better when a coarser resolution (NCEP) meteo forcing is used, with the model output using the high resolution BADC meteo data being persistently lower than observations. Errors increase during the summer, reaching approximately $-1.15^{\circ} \mathrm{C}$ in August after the period of strongest solar radiation in July. As the BADC and NCEP data vary in their mean values of cloudiness, wind speed, and air temperature, this in turn influences sea-air heat exchange and thus the sea surface temperature output of the POLCOMS model. Refinements in resolution of the meteorological forcing do not, therefore, necessarily correlate directly with improvements in oceanographic model performance and should not be considered in isolation.

\section{Acknowledgments}

This work is supported partly by EU FP7 MyOcean and a Plymouth University CENORE Ph.D. studentship.

\section{References}

[1] D. G. Wright and T. F. Stocker, "Sensitivities of a zonally averaged global ocean circulation model," Journal of Geophysical Research, vol. 97, no. 8, pp. 12-730, 1992.

[2] T. Ezer and G. L. Mellor, "A generalized coordinate ocean model and a comparison of the bottom boundary layer dynamics in terrain-following and in z-level grids," Ocean Modelling, vol. 6, no. 3-4, pp. 379-403, 2004.

[3] S. Legg, R. W. Hallberg, and J. B. Girton, "Comparison of entrainment in overflows simulated by z-coordinate, isopycnal and non-hydrostatic models," Ocean Modelling, vol. 11, no. 1-2, pp. 69-97, 2006.

[4] G. Shapiro, M. Luneva, J. Pickering, and D. Storkey, "The effect of various vertical discretization schemes and horizontal diffusion parameterisation on the performance of a 3D ocean model: the Black Sea case study," Ocean Science Discussion, vol. 9, no. 6, pp. 3643-3671, 2012.

[5] S. L. Wakelin, J. T. Holt, and R. Proctor, "The influence of initial conditions and open boundary conditions on shelf circulation in a 3D ocean-shelf model of the North East Atlantic," Ocean Dynamics, vol. 59, no. 1, pp. 67-81, 2009.
[6] J. Berntsen, J. Xing, and A. M. Davies, "Numerical studies of flow over a sill: sensitivity of the non-hydrostatic effects to the grid size," Ocean Dynamics, vol. 59, no. 6, pp. 1043-1059, 2009.

[7] G. I. Shapiro, "Effect of tidal stream power generation on the region-wide circulation in a shallow sea," Ocean Science, vol. 7, no. 1, pp. 165-174, 2011.

[8] E. F. Young and J. T. Holt, "Prediction and analysis of long-term variability of temperature and salinity in the Irish Sea," Journal of Geophysical Research C, vol. 112, no. 1, 2007.

[9] C. K. O’Neill, J. A. Polton, J. T. Holt, and J. E. O’Dea, “Modelling temperature and salinity in Liverpool Bay and the Irish Sea: sensitivity to model type and surface forcing," Ocean Science Discussions, vol. 8, no. 5, pp. 903-913, 2012.

[10] K. R. Thompson and D. T. Pugh, "The subtidal behaviour of the Celtic Sea-II. Currents," Continental Shelf Research, vol. 5, no. 3, pp. 321-346, 1986.

[11] D. A. Huntley, “Tides on the northwest European Continental shelf," in North-West European Shelf Seas: Physical and Chemical Oceanography and Physical Resources V. 2: Sea Bed and the Sea in Motion, F. T. Banner, Ed., Elsevier oceanography series, pp. 301-351, 1980.

[12] A. J. Manning, W. J. Langston, and P. J. C. Jonas, "A review of sediment dynamics in the Severn Estuary: influence of flocculation," Marine Pollution Bulletin, vol. 61, no. 1-3, pp. 3751, 2010.

[13] E. F. Young, J. Brown, J. N. Aldridge, K. J. Horsburgh, and L. Fernand, "Development and application of a three-dimensional baroclinic model to the study of the seasonal circulation in the Celtic sea," Continental Shelf Research, vol. 24, no. 1, pp. 13-36, 2004.

[14] R. D. Pingree, "Physical oceanography of the Celtic sea and English channel," in The North-West European Shelf Seas: The Sea Bed and the Sea in Motion II Physical and Chemical Oceanography and Physical Resources, F. T. Banner, W. B. Collins, and K. S. Massie, Eds., pp. 415-465, Elsevier, Oxford, UK, 1980.

[15] J. Brown, L. Carrillo, L. Fernand et al., "Observations of the physical structure and seasonal jet-like circulation of the Celtic Sea and St. George's Channel of the Irish Sea," Continental Shelf Research, vol. 23, no. 6, pp. 533-561, 2003.

[16] J. T. Holt and I. D. James, "An s coordinate density evolving model of the northwest European continental shelf 1, Model description and density structure," Journal of Geophysical Research C, vol. 106, no. 7, pp. 14015-14034, 2001.

[17] J. T. Holt, I. D. James, and J. E. Jones, "An s coordinate density evolving model of the northwest European continental shelf 2, seasonal currents and tides," Journal of Geophysical Research C, vol. 106, no. 7, pp. 14035-14053, 2001.

[18] J. Holt, S. Wakelin, J. Lowe, and J. Tinker, "The potential impacts of climate change on the hydrography of the northwest European continental shelf," Progress in Oceanography, vol. 86, no. 3-4, pp. 361-379, 2010.

[19] C. E. Enriquez, G. I. Shapiro, A. J. Souza, and A. G. Zatsepin, "Hydrodynamic modelling of mesoscale eddies in the Black Sea," Ocean Dynamics, vol. 55, no. 5-6, pp. 476-489, 2005.

[20] C. K. O'Neill, A study of dense water formation over Rockall Bank [Ph.D. thesis], University of Plymouth, 2008.

[21] G. I. Shapiro, "Effect of tidal stream power generation on the region-wide circulation in a shallow sea," Ocean Science, vol. 7, no. 1, pp. 165-174, 2011.

[22] M. Bell, "Ocean Forecasting-progress and plans," 2012, http:// www.metoffice.gov.uk/media/pdf/f/d/MOSAC_17.7_MBell.pdf. 
[23] A. Arakawa, "Design of the UCLA general circulation model," Tech. Rep. 7, University of California, Los Angeles, Calif, USA, 1972.

[24] Y. Song, "A semi-implicit ocean circulation model using a generalized topography-following coordinate system," Journal of Computational Physics, vol. 115, no. 1, pp. 228-244, 1994.

[25] P. Colella and P. R. Woodward, "The Piecewise Parabolic Method (PPM) for gas-dynamical simulations," Journal of Computational Physics, vol. 54, no. 1, pp. 174-201, 1984.

[26] L. Umlauf and H. Burchard, "A generic length-scale equation for geophysical turbulence models," Journal of Marine Research, vol. 61, no. 2, pp. 235-265, 2003.

[27] “ETOPO2v2 Global Gridded 2-minute Database," National Geophysical Data Center, National Oceanic and Atmospheric Administration, U.S. Dept. of Commerce, 2006, http://www .ngdc.noaa.gov/mgg/global/etopo2.html.

[28] T. Boyer, S. Levitus, H. Garcia, R. A. Locarnini, C. Stephens, and J. Antonov, "Objective analyses of annual, seasonal, and monthly temperature and salinity for the World Ocean on a 1/4 grid," International Journal of Climatology, vol. 25, no. 7, pp. 931945, 2005.

[29] G. D. Egbert, S. Y. Erofeeva, and R. D. Ray, "Assimilation of altimetry data for nonlinear shallow-water tides: quarter-diurnal tides of the Northwest European Shelf," Continental Shelf Research, vol. 30, no. 6, pp. 668-679, 2010.

[30] C. J. Willmott, "On the validation of models," Physical Geography, vol. 2, no. 2, pp. 184-194, 1981. 

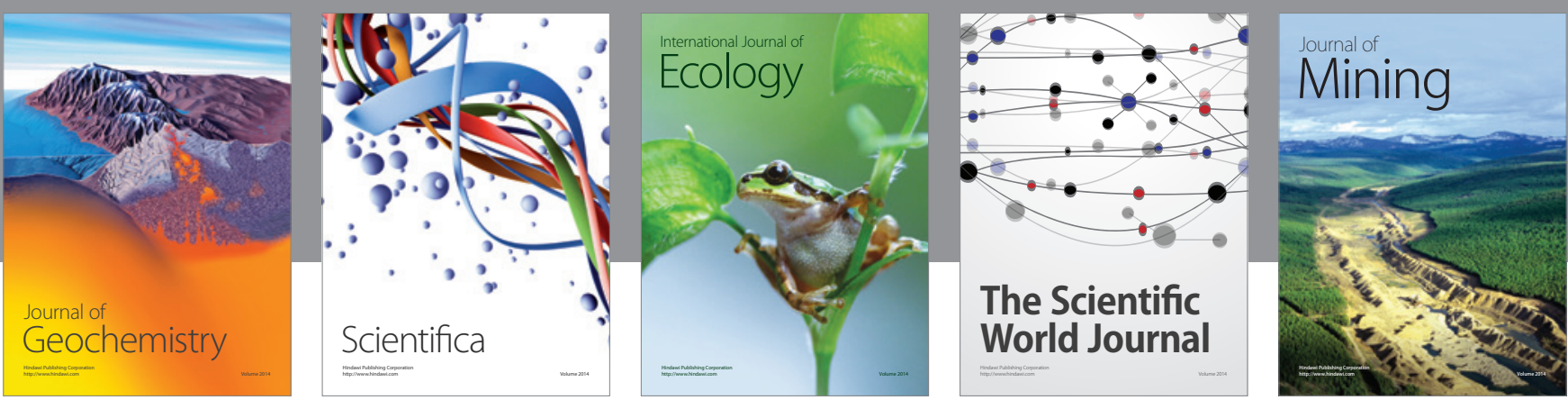

The Scientific World Journal
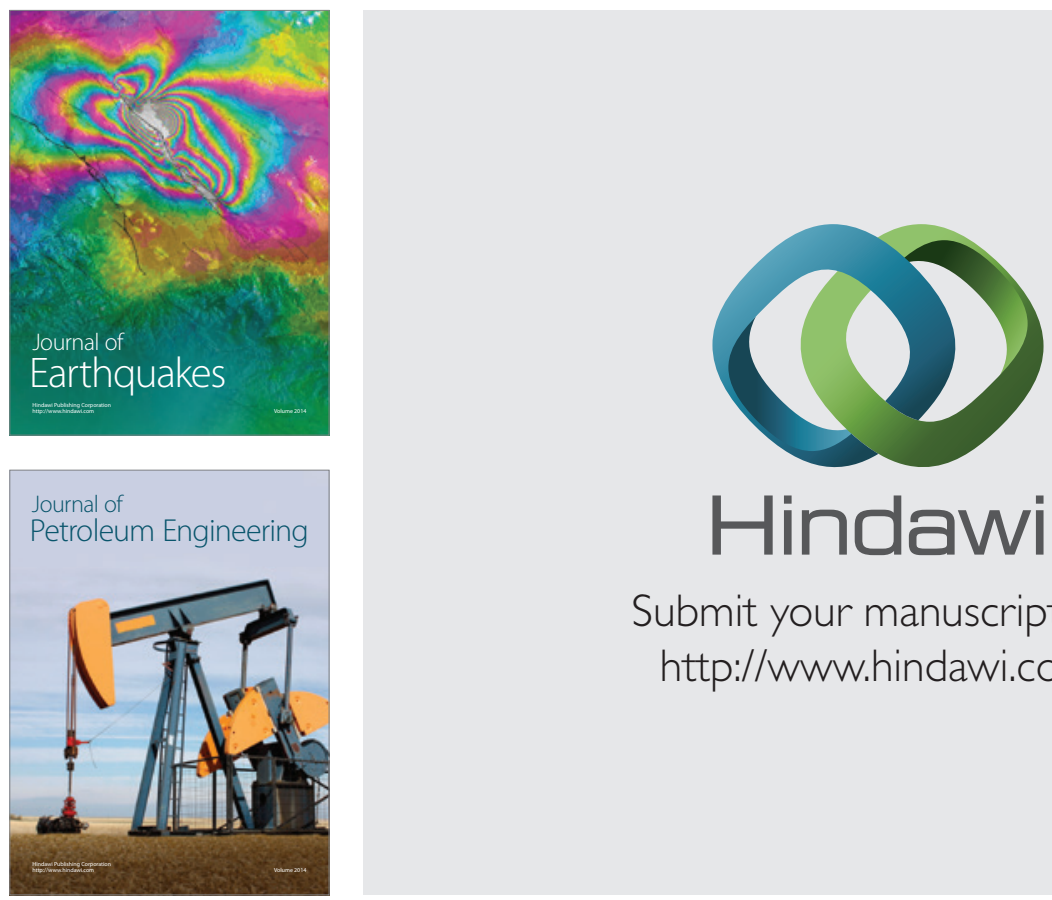

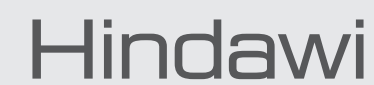

Submit your manuscripts at

http://www.hindawi.com
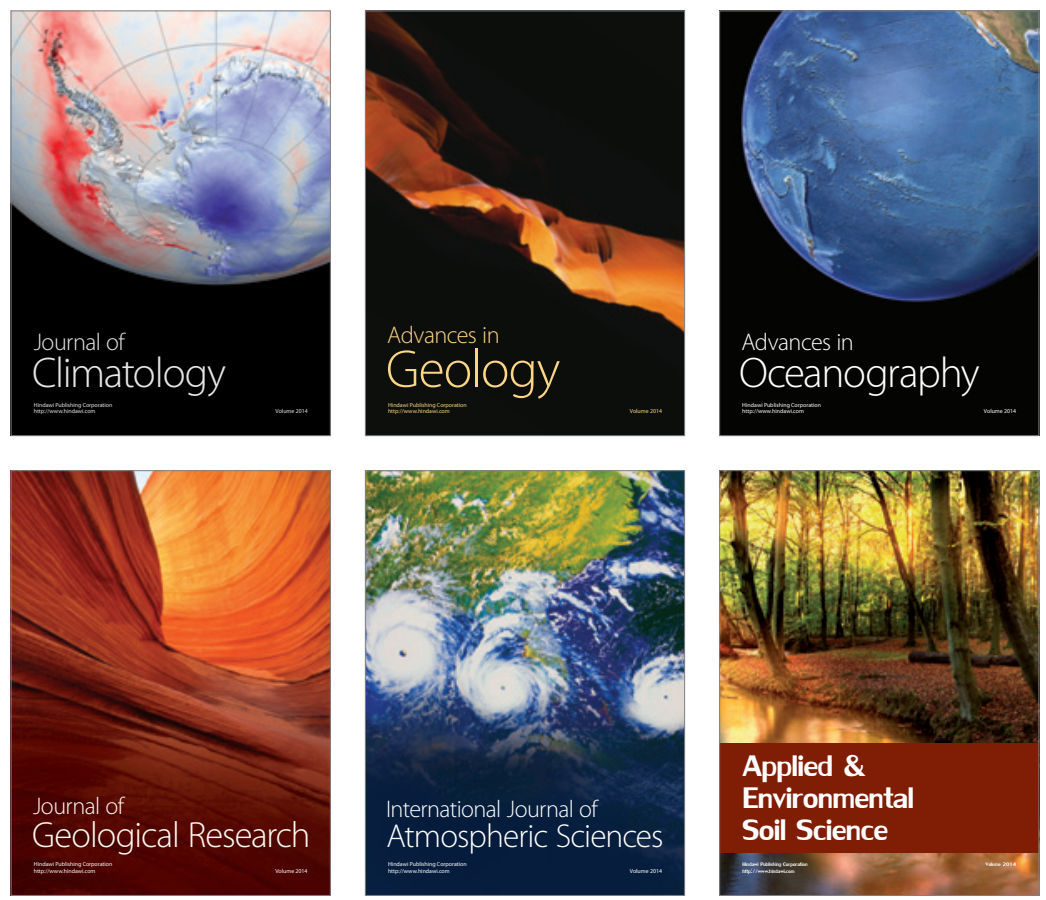
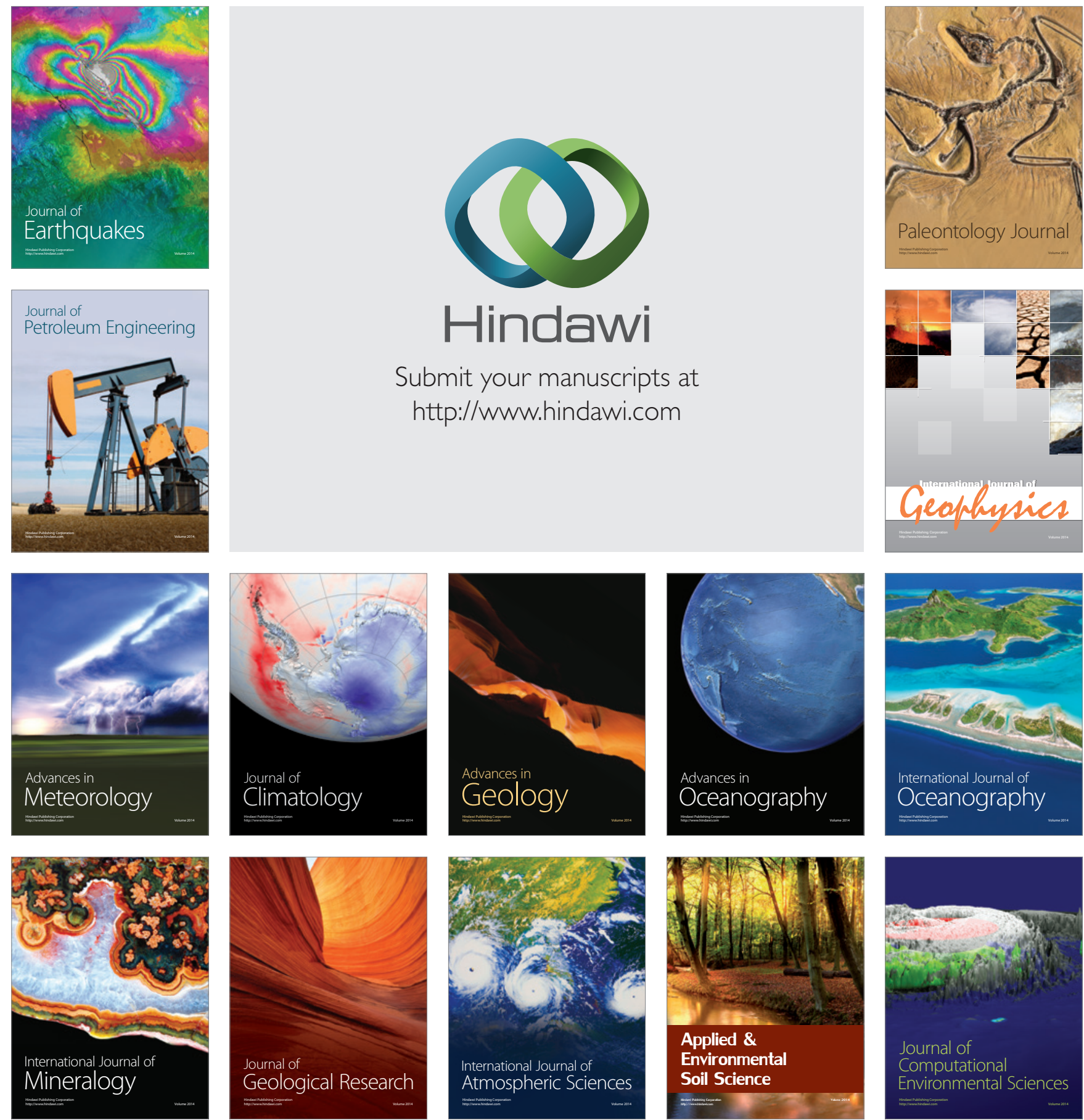